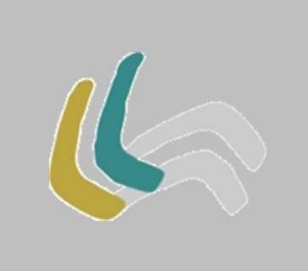

\title{
UM SENTIMENTO TÃO FEIO QUANTO O TORPOR
}

A FEELING AS UGLY AS NUMBNESS

\author{
Ruan Nunes Silva ${ }^{1}$ \\ Universidade Estadual do Piauí
}

Resumo: Este trabalho tem como objetivo analisar de que formas o torpor, um afeto tradicionalmente lido como negativo, pode ser útil quando se interrogam as estruturas sociais heteronormativas. Para tal, uma leitura do torpor na obra Chelsea Girls de Eileen Myles é realizada com o intuito de sublinhar as interpretações do estado de entorpecimento nas interações da protagonista da obra com o mundo ao seu redor. Considerando as contribuições de Muñoz (1999), Despentes (2016), Ahmed (2010) e outros, pode-se concluir que o torpor é um afeto complexo que, em negociações que não estão isentas de sofrimento, revela inconsistências no cenário social político ao questionar o que se convencionou chamar de "sentimentos bons". Desta forma, o torpor se torna um "sentimento feio" com usos políticos possíveis.

Palavras-Chave: Afetos; Estudos queer; Chelsea Girls; Eileen Myles; Torpor.

1 Endereço eletrônico: ruan@phb.uespi.br. 
Abstract: This paper aims to analyse the ways in which numbness, an affect traditionally seen as negative, may be useful when interrogating heteronormative social structures. For this end, a reading of numbness in Eileen Myles's Chelsea Girls is carried out so as to highlight the interpretations of the state of numbness in the interactions the protagonist establishes with the world around her. Considering the contributions of theorists such as Muñoz (1999), Despentes (2016), Ahmed (2010) among others, it may be concluded that numbness is a complex affect which, in negotiations not devoid of suffering, reveals inconsistencies in our social and political scene by questioning what has been conventionally named "good feelings". This way, numbness becomes an "ugly feeling" with possible political uses.

Keywords: Affects; Queer studies; Chelsea Girls; Eileen Myles; Numbness.

A primeira mulher colocou a cabeça entre as minhas pernas e o pecado se completou, o momento absoluto do sexo se refez e eu virei uma peça completa que se decompunha. Eu estava disposta a sacrificar tudo por aquele momento. Inclusive minha buceta, aquele vaso.

Eileen Myles (2019)

\section{INTRODUÇÃO}

Em alguns espaços - acadêmicos ou não - ainda temos discussões acaloradas sobre como determinadas obras não nos edificam. Acontecem em salas de aula, livrarias e até mesmo em eventos acadêmicos, como indica a notícia de Justin Tackett (2014) sobre um evento que discutiu literatura e moralidade na Universidade de Stanford. Nesses debates, tais obras são "responsáveis" por desvirtuarem o cânone, poluírem as mentes e desvalorizarem todas as expressões literárias que existem. Tudo isso e mais um pouco já foi dito sobre Chelsea Girls, obra da poeta e escritora estadunidense Eileen Myles como sublinham Jack (Judith) Halberstam (2005) e Rachel Hurn (2013). Ao rechear as páginas de seu livro com sexo descompromissado, cenas de uso e abuso de drogas e também inadequação social, a autora escreve sobre como Eileen, a protagonista, se aproxima mais da decadência moral do que do belo associado aos estereotipados valores femininos. Contudo, uma incômoda pergunta permanece: por que Eileen, a personagem, escolhe um caminho das coisas sujas demais, o caminho de um 
sentimento tão feio quanto o torpor? Para tentar me aproximar de respostas possíveis, traço dois momentos nesta reflexão.

No primeiro, intitulado "Sentimentos Feios", apresento brevemente a base teórica pela qual me aproximo do livro Chelsea Girls. Nesta parte ofereço uma reflexão sobre o que significa falar sobre afetos, sentimentos e/ou emoções considerados feios, negativos ou ruins, especialmente quando indago a relação entre afetos e corpos sociais. Uma discussão sobre os afetos e as formas pelas quais são interpretados pode, na minha leitura, oferecer novas possibilidades investigativas nos campos feministas e/ou queer, especialmente para além de indagações sobre identidades como construções essencialistas e monolíticas. As contribuições teóricas de nomes como Sianne Ngai (2005), Sara Ahmed (2010) e Virginie Despentes (2016) permitem refletir sobre essa relação entre corpos e afetos, ressignificando determinados lugares-comuns.

No segundo momento, "'Você fica bêbada toda noite'”, investigo como a obra Chelsea Girls, escrita por Eileen Myles, desafia a compreensão do entorpecimento como uma prática improdutiva, como um "sentimento feio" que deveríamos evitar. Evitando cair no utopismo de que o torpor é uma saída viável, leio que a protagonista, Eileen, se desidentifica e consegue negociar sentidos a partir de sua relação complexa com o estado de entorpecimento constante. Nessa leitura busco pensar que a desidentificação, como proposta por José Esteban Muñoz (1999), é uma estratégia de sobrevivência de grupos minoritários e que se relaciona com os afetos que nos fazem sentir o fracasso. Contudo, o fracasso é aqui lido à luz de Jack Halberstam (2020) que enxerga nele formas de inadequação em sistemas que buscam normalizações. Argumento que Eileen consegue, por meio do "sentimento feio" do torpor, se inadequar como forma de vida e, não sem sofrimento, destacar que existem possibilidades para além do binarismo estabelecido por regimes heteropatriarcais. 
Profundamente influenciado pela discussão proposta por Sianne Ngai (2005) em Ugly Feelings, acredito ser necessário estabelecer uma distinção entre o que chamo de sentimentos bonitos e sentimentos feios. Ngai afirma que os afetos abordados em sua obra não possuem características morais (ou imorais) ou mesmo catárticas e, por isso, não oferecem possibilidades virtuosas de alívio ou liber(t)ação de si. Em outras palavras, o que a crítica investiga em Ugly Feelings é como os afetos considerados ruins e negativos são expressões de sentimentos e/ou emoções que não buscam redimir ou mesmo criar laços (bons ou ruins) com a audiência. Dessa forma, com esses "sentimentos feios" não se aprenderia a ser um sujeito melhor ou mesmo pior, permanecendo o impasse que sustenta a dificuldade afetiva de determinadas obras fílmicas e literárias que ela investiga.

Há, contudo, um detalhe interessante que não recebe grande destaque na escrita de Ngai, mas que me é caro ao pensar a literatura. Mesmo que se pense a amoralidade como parte integral do projeto afetivo que ela desenvolve, ao traçar sentimentos que ela considera "feios", há um inegável jogo de (i)moralidades quando se pensa quem considera tais sentimentos ruins. Em outras palavras, o objetivo da teórica é sublinhar que os afetos deveriam ser pensados amoralmente como sintomáticos de construções sociais que direcionam esses sentimentos "feios" para alguns corpos, mas desde já sinalizo que não acredito ser possível se aproximar das artes sem considerar que alguém elabora uma crítica a partir de um espaço social imbuído de valores e negociações de sentidos. Ngai, por exemplo, ressalta que em Quicksand de Nella Larsen a irritabilidade/irritação é uma constelação afetiva na qual raça e gênero não podem ser ignorados justamente por informarem a irritabilidade que a protagonista do romance sente constantemente como uma mulher que não se compreende branca ou negra. É impossível, portanto, negar a relevância de posicionar quem decide que tais afetos 
são feios e negativos e de que formas eles são compreendidos ou mesmo projetados em determinados corpos: alguns corpos se tornam fontes desses afetos ruins.

Leio essa preocupação sobre quem decide quais os valores afetivos de uma obra especialmente quando Ngai afirma que seu livro é um bestiário de afetos, cheio de ratazanas e gambás em vez de leões. Aqui ela está também estabelecendo um julgamento de que tais sentimentos ratazanescos ou gambazentos são leituras que os agrupam como fracos, ruins, indecentes e também imorais em algum nível não apenas para um público, mas especialmente a partir de um ponto de vista específico. Esses afetos não são imorais no sentido de que existe uma imoralidade inata, mas sim porque expressam uma discordância possível de determinados discursos sociais que moldam espaços e relações. Desse modo, estabeleço uma diferença crucial entre o que chamo de sentimentos bonitos/bons/positivos e feios/ruins/negativos: o primeiro grupo é, inevitavelmente, o que os discursos e as instituições sociais buscam assentar em nossas vidas, mantendo uma aparente ordem natural do que seria "correto", enquanto o segundo grupo de sentimentos seriam aqueles que idealmente precisamos evitar porque eles não só nos "pioram" como sujeitos, mas também não são socialmente corretos e benéficos.

Penso aqui, por exemplo, nas formas pelas quais a raiva ou a tristeza são lidas como expressões de incapacidade de agir, gerando diversos tipos de imobilização social. Essas leituras negativas são questionadas por uma virada afirmativa que se preocupa com questões como finais felizes e representatividade expressiva. Essa virada afirmativa recusa a negatividade que parece ser a grande morada de estudos LGBTQ+, abrindo espaço para as formas de felicidade possíveis para sujeitos minoritários. Contudo, seguindo Jack Halberstam (2020) e Sara Ahmed (2010), desconfio da produtividade otimista que tal virada oferece. Parece-me mais desafiador compreender o que podemos fazer com a raiva e a 
tristeza do que apenas apagá-la do arquivo literário contemporâneo em prol de uma versão mais limpa e menos triste dos estudos queer. Como bem nos lembra Halberstam (2020, p. 21):

[...] ainda que, indubitavelmente, o fracasso venha acompanhado de uma horda de emoções negativas, tais como decepção, desilusão e desespero, ele também proporciona a oportunidade de usar essas emoções negativas para espetar e fazer furos na positividade tóxica da vida contemporânea.

É este viés, o de pensar os sentimentos feios como possíveis reconfigurações políticas, ao qual me atenho na discussão afetiva de Chelsea Girls. Narrativas que são lidas como retrógradas (LOVE, 2009) não são necessariamente espaços de aprendizagem para entusiastas da virada positiva nos estudos queer, mas as releituras de sentimentos negativos podem indicar inspiração para pensar que essa virada positiva tem - como toda teoria - suas falhas. Tal como Léa Menezes de Santana (2019, p. 121), busco inspiração "nestas identidades tidas como periféricas, malvistas, sujas [...] para pensar em novos caminhos para o feminismo, ampliando campos de ação onde a luta pela emancipação feminina pode acontecer". Embora o termo identidade sugira certa fixidez, a proposta de indagar o que formam essas figuras "periféricas, malvistas, sujas" se sustenta também nessa virada afetiva na qual negocio preocupações feministas e queer.

É necessário apontar, portanto, que um afeto proeminentemente discutido aqui - o torpor - é justamente produtivo porque ele é comumente lido como negativo, indesejado e, se possível, algo a ser evitado. Estar ou encontrar-se entorpecido é reconhecer o estado de paralisia no qual os sujeitos estão não só mentalmente incapazes de responder por si, mas também um estado no qual o corpo não responde aos nossos chamados cognitivos. Estar entorpecido pode ser efeito de alguma situação ou substância, de um acontecimento ou de uma resposta para não viver um acontecimento. Destaco aqui um caráter fundamental do entorpecimento para a minha leitura: o entorpecimento interrompe a 
tradicional (e ultrapassada) interpretação cartesiana da soberania da mente sobre o corpo, afinal, estar entorpecido é justamente negar a soberania de qualquer um sobre o outro.

Sugerir que o torpor é então uma experiência que interroga a soberania da mente é sublinhar a associação da razão com a construção do mundo. Escolher estar entorpecido é uma ação socialmente lida como uma fuga das responsabilidades, uma escolha pela irresponsabilidade em relação ao que se espera de sujeitos em um mundo cada vez mais predatório no qual nossos sentimentos são constantemente manufaturados para não fugirem do índice proposto pela sociedade. O torpor pode também ser pensado como uma recusa bartlebyana: recusar é, como no famoso conto de Hermann Melville, uma possibilidade de não se comprometer com o mundo que deseja comprometimento. Ao escolher o torpor como sítio de novas possibilidades de existência, noto que a vida proposta nos moldes neoliberais entra em curtocircuito justamente porque a recusa não é apenas sobre ocupar um lugar previamente decidido, mas também uma recusa pelo lugar da oposição tal qual Bartleby.

Um corpo que se recusa a ocupar é um corpo que destoa. Um corpo que escolhe o torpor é um corpo que recusa a racionalidade justamente porque escolhe não só agir contraintuitivamente, mas agir contra o lugar-comum (HALBERSTAM, 2012). A escolha pelo torpor é uma decisão que ofende e suscita abjeção porque recusa o lugar-comum de que o bom senso deveria nos guiar. A consciência perde seu lugar de primazia quando sujeitos escolhem não ser guiados pela racionalidade que é ofertada como objetividade e retidão. Pelo contrário, corpos entorpecidos preferem outros modos de existir, recusando o vínculo com um sistema reprodutivo de identidades e identificações.

Diana Klinger (2014) nos lembra da importância de deslocar a pergunta do que pode uma consciência para o que pode um corpo, destacando que os corpos 
são então produzidos a partir de seus encontros e não mais a partir de uma matéria inata. Assim, produz-se uma curiosa forma de indagar como as produções de corpos são, na realidade, formas de produções sociais. Cabe lembrar aqui que ao falar de corpos, não sugiro apenas corpos humanos, mas sim objetos, sentimentos, ideias, coisas, palavras: esses encontros nos formulam constantemente. Um exemplo clássico dos estudos queer é a performatividade de gênero de Judith Butler (2015) na qual a construção de gênero/sexo é um grupo de produções fictícias que sustentamos no encontro com determinados discursos e instituições. Só existimos como homens e mulheres porque certos dispositivos nos modelam como tais e para tal fim. Por esse motivo parece-me essencial destacar que aquilo que chamamos de sentimentos feios ou bonitos são também produções que nos interpelam, formulando aquilo que tentamos chamar de consciência ou mesmo identidade. Daí a necessidade de perguntar o que um corpo pode fazer em seus encontros e não mais centralizar as experiências na compreensão de uma consciência que nos formaria, independente de relações sociais. Somos o que somos porque estamos constantemente nos fabricando e sentimos o que sentimos porque também estão nos informando sobre como sentir. Se alguém escolhe o torpor, o que há nessa ação? O que essa escolha nos diz sobre o que também sentimos? Será que estar entorpecido é então apenas uma forma de irresponsabilidade ou há algo de escolha que pode nos fazer pensar sobre o nosso sistema?

A escolha pela negociação de si com o mundo das abjeções não pode ser pensada como um simples passeio pelo mundo dos vícios. Contudo, pensando no mundo das artes, por que algumas obras que tematizam a sujeira, as drogas, os vícios, o sexo descompromissado etc, são lidas como problemáticas, censuráveis e desnecessárias? Não haveria algo a aprender com todo esse cenário fictício que lida com a sujeira do sistema? Seria melhor, talvez, apagar essas existências e fingir que nunca existiram? A escritora e cineasta francesa Virginie 
Despentes nos lembra que apenas ignorar uma situação não fará a questão desaparecer:

Nós sempre existimos. Mesmo que nunca se fale de nós nos romances escritos por homens, que eles só consigam imaginar mulheres com as quais gostariam de transar. Nós sempre existimos - mas nunca falamos. Mesmo hoje, quando muitas mulheres publicam romances, raramente encontramos personagens femininas de aspecto físico desagradável ou medíocre, incapazes de amar os homens ou de serem amadas por eles. (DESPENTES, 2016, p. 8)

Em Teoria King Kong Despentes escreve sobre o que significa ser uma mulher suja e feia em espaços nos quais a feminilidade é essencializada a partir de signos aos quais todas as mulheres deveriam aderir. Ao se posicionar escrevendo "a partir da feiura e para as feias, as caminhoneiras, as frígidas, as mal comidas, as incomíveis, as histéricas, as taradas, todas as excluídas do grande mercado da boa moça" (DESPENTES, 2016, p. 7), a autora sinaliza a sua ambivalência desidentificatória - tema a ser discutido ainda aqui. É sobre esse não-lugar, um espaço dos sentimentos feios, que o presente trabalho trata. Pensar não mais os afetos negativos como elementos de narrativas tristes que nada podem nos dizer sobre a situação de sujeitos LGBTQ+. Pelo contrário, os sentimentos feios como raiva, tristeza, nojo e torpor podem nos ensinar sobre como os corpos não só habitam espaços discursivamente criados, mas como podem desconfigurar esse próprio sistema.

Se até aqui busquei apresentar uma discussão sobre como os sentimentos feios nos produzem a partir da compreensão de que não deveríamos senti-los porque seriam formas de diminuir nossas potências no mundo, repito que esses mesmos sentimentos feios só são considerados feios porque eles interrompem determinados discursos de felicidade. Ao tratar da felicidade como um afeto problemático, Sara Ahmed (2010) afirma que seguir alguns "scripts de felicidade" [happiness scripts] seria uma forma de se aliar ao que seria bom no mundo e, 
consequentemente, nos aproximarmos daquilo que nos tornaria felizes. Seguir esses scripts de felicidade nos aproximaria de uma vida feliz na qual sentiríamos apenas coisas boas e evitaríamos ao máximo os sentimentos ruins. Contudo, o que acontece quando essa vida feliz é, na realidade, uma ficção sustentada também por ilusões? O que acontece quando compreendemos que o casamento é uma forma de assimilação (BOURCIER, 2020), que o amor é uma relação de trabalho (KIPNIS, 2004), que uma vida feliz é impossível porque estamos vivendo vidas precarizadas (BERLANT, 2011)? Uma possível resposta é compreender como esses sentimentos feios interromperiam essas ilusões de uma vida feliz justamente porque esses ideais de felicidade não só estão atrelados a determinados afetos "bons", mas principalmente a discursos que compreendem algumas formas de vida como possíveis e outras como impossíveis.

\section{2 "VOCÊ FICA BÊBADA TODA NOITE"}

Publicado originalmente em 1994, Chelsea Girls é um romance que desafia diversas normas de gênero - gender e genre. Embora seja um romance, Chelsea Girls pode também ser lido como uma coletânea de histórias/crônicas. Não há uma narrativa linear e somos constantemente arrastados temporalmente por diversos momentos dos anos 1970, atravessando narrativas sobre família disfuncionais, amantes com problemas, casos de pobreza e uma generosa quantidade de sexo e drogas. Chelsea Girls é, portanto, um livro que se distancia profundamente dos sentimentos associados aos bons costumes.

“Eu não tinha porra nenhuma para fazer lá. Quer dizer, por que será que moro com a minha ex-namorada e sua nova namorada, e a ex-namorada dela. Como é que alguém pode se sentir bem assim" (MYLES, 2019, p. 9, grifo da autora). Assim inicia Chelsea Girls. Há uma expressa indicação de que algo na obra destoará do tecido social heteronormativo. Eileen, a protagonista, descreve 
o caos de morar com essas mulheres que foram ex e agora são namoradas, destacando a própria incapacidade de se sentir bem, afinal, para viver bem deverse-ia morar com um parceiro único e não com essas mulheres. Já há um processo curioso de desidentificação que permeará toda a obra.

Em Disindentifications José Esteban Muñoz (1999) desenvolve o conceito de desidentificação a partir das leituras de nomes como Michel Pêcheux e Judith Butler. Muñoz nos lembra que sujeitos que são parte de grupos considerados minoritários (mulheres que não são brancas, sujeitos LGBTQ+) empregam diversas estratégias para sobreviver ao/no mundo de heteronormatividade. Dessa forma, as desidentificações são as formas pelas quais esses sujeitos minoritários negociam sentidos dentro de matrizes de opressão que os leem como sujeitos que fogem da regra. Desidentificar-se não é, portanto, apenas uma expressão de concordar com o sistema ou apenas recusá-lo, mas sim reconhecer de que formas esses sujeitos localizam na esfera pública formas outras de existir que esbarram nas duas compreensões de aceitar e recusar o próprio sistema.

A desidentificação é um processo de "ler a si mesmo e a sua narrativa de vida em um momento, um objeto ou um sujeito que não está culturalmente codificado para se 'conectar' com o sujeito que se desindentifica" (MUÑOZ, 1999, p. 12). Assim, desidentificar-se é compreender de que formas algumas identificações são perigosas, mas que nem por isso devem ser apagadas porque elas formam uma crítica do próprio sistema que as sustenta. Não se trata, portanto, de escolher uma identificação e recusar outra, mas habitar um espaço complexo e polêmico no qual o sujeito que se desidentifica produz novos sentidos a partir da matriz que esse mesmo sujeito deglute e recusa, devora e cospe. Muñoz diz, por exemplo, que um movimento de desidentificação é a forma pela qual sujeitos minoritários desejam o ideal branco de classe média, mas, ao mesmo tempo, se desfazem dele ao interseccionarem as discussões de desejo e ideologia como um projeto de questionar o ideal branco pelo qual seriam 
aceitos. Esse processo de manter a ordem no lugar ao mesmo tempo que a subverte é uma estratégia complexa de marcar determinadas existências e não apenas uma prática inocente de aceitar/recusar alguns modelos existentes. Desidentificar-se é reconhecer os processos de fabricação de encontros de traços nem sempre harmoniosos dentro da sociedade como forma de sobreviver e manter-se vivo ou viva.

Em Chelsea Girls a protagonista Eileen é um sujeito que se desidentifica constantemente. Ela negocia os valores aos quais ela adere, mas que, ao mesmo tempo, critica e desfaz. Dessa forma, penso que uma leitura que considere Eileen apenas como uma mulher degenerada esteja ignorando as formas pelas quais ela também aceita os discursos normativos para poder subvertê-los. A própria ideia de degeneração é uma imbuída de moralizações que o afeto do torpor pode desfigurar quando aproximo a discussão sobre afetos e sentimentos de Chelsea Girls.

De maneira instigante, Eileen descreve como se sente em vários momentos da obra. Sentir é uma forma de se posicionar no mundo e compreender que é uma tentativa de desidentificação daquilo que lhe vendem como uma vida possível.

Já tinha determinado que não estava mais apaixonada pela Chris, tinha decidido ser uma espectadora impassível, seria um prazer não dar importância pra isso. E daí se eu não sabia mais o que sentia? Provavelmente eu nunca soube o que sentia. Gosto mesmo é de ficar bêbada e estar apaixonada. Se eu não estava nem uma coisa nem outra, eu só queria poder pagar meu aluguel, meus cigarros, o café, só isso. Eu gostava muito da vida de poeta. (MYLES, 2019, p. 15-16, grifo nosso)

É curioso que, conforme grifado no trecho acima, Eileen enfatize tanto a ideia de sentir como forma de estar no mundo. Ao contrário de outras pessoas, ela parece destacar que seu desejo não é pelos mesmos objetos que outros atribuem felicidade e sucesso, dois da pletora de signos que indicam sujeitos que 
vivem boas vidas. Ao trazer já no início de Chelsea Girls que a sua preocupação é com o que os seus sentimentos lhe informam sobre seu lugar em vários espaços sociais, Myles, a escritora, está, por meio de Eileen, a personagem, desfazendo o caminho dos processos de normalização de sujeitos. Myles está, portanto, falando desde o início sobre os sentimentos feios por meio de Eileen.

Retorno à discussão dos sentimentos feios para traçar como Eileen é uma mulher preocupada com aquilo que não a tornará uma pessoa melhor. Pelo contrário, ao sublinhar seu interesse pelas coisas sujas da sociedade como drogas, sexo e pobreza, ela está marcando seu lugar em narrativas não apenas tradicionalmente associadas aos homens, mas principalmente seu lugar a partir daquilo que a sociedade a informa sobre o que não deveria ir atrás. Ao se deliciar com aquilo que é sujo e imoral, Eileen está também desfazendo a narrativa da vida feliz à qual muitos anseiam. Desse modo, ela consegue revelar as inconsistências do sonho de uma vida feliz vendida como um meio de estar no mundo, como ela discute ao narrar sua ligação com um casal com o qual mantinha relações:

Minha grande forma de sobreviver, parecia, era me envolver com essas famílias. Eles nem se falavam mais ou talvez tivessem só relacionamentos de trabalho, mas pareciam pensar secretamente que estavam fazendo "isso" de um jeito errado, ou dando seu melhor ou os únicos que estavam fazendo alguma coisa. Era difícil saber de qual "isso" se tratava. Crescer é difícil pra todo mundo e eu acho que, para os heterossexuais, o "isso" aparece quando eles têm filhos e passa a haver algo externo ao seu relacionamento que não são os amigos e esse motivo basta para que não se desista. Continuar é como escapar de si mesmo o tempo todo. Eu adorava ficar sentada ali ouvindo sobre o "isso" deles. (MYLES, 2019, p. 148)

Envolver-se com famílias consideradas tradicionais - um casal, um homem e uma mulher, um casamento, uma relação heterossexual - era uma forma de sobreviver não só financeiramente, porque ela conseguia dinheiro e comida com eles eventualmente, mas também uma experiência dentro da 
heteronormatividade em um dos espaços de controle. Eileen descreve que nem mesmo as pessoas nas relações heterossexuais conseguem descrever o que seria esse "isso" sobre o qual se fala. "Isso" seria aquilo que muitas pessoas buscam e não conseguem descrever justamente porque é "isso" que é indescritível pela sua ausência de sentido. Envolver-se com pessoas heterossexuais é uma forma de questionar e interrogar o sistema que informa que esse "isso" deve ser preenchido por instituições e discursos sociais como casamento, relações monogâmicas, empregos respeitáveis, relações dignas etc.

Ngai (2005) descreve que quando a inveja é moralizada e feminizada, ela opera para suprimir o seu potencial de reconhecimento de desigualdades porque ela permite levantar suspeitas sobre as condições nas quais ela surge. De maneira semelhante, Eileen consegue usar de sua presença em relações heterossexuais para "bagunçar o coreto": sua presença como sujeito bi/queer, se relacionando com homens e mulheres, é uma nódoa no tranquilo tecido da heteronormatividade, afinal, ela demonstra que mesmo o casamento, tradicional instituição à qual todos deveriam aspirar, é também uma ficção que não se sustenta. A aparente devassidão é, na realidade, uma prática queer de recusar ordens fixas para um afeto tão complexo como o amor.

Eileen recusa a ideia de pertencimento por acreditar que pertencer seria uma forma de assimilação dos valores do status quo, logo uma forma de existir com a qual ela não concorda: "Se há uma coisa que sempre carreguei comigo é essa falta de vontade de ser parte de um grupo, uma geração inteira, terrível, entoando 'vamos nessa!' e à qual eu pertencia”' (MYLES, 2019, p. 203). Recusar é empreender uma tarefa crítica de avaliar o sistema e perceber que os ideais que deveria desejar são formas de aprisionamento de sua expressão como sujeito. Não por acaso, reconhecendo que precisa de meios para (sobre)viver, Eileen utiliza o álcool e outras substâncias como um escape das narrativas de normalização e mesmo dos scripts de felicidade: "Estava chovendo e senti que o 
ácido já começava a bater enquanto eu caminhava pela Quinta Avenida. Eu adorava esses momentos de privacidade intensa que as drogas proporcionavam [...]" (MYLES, 2019, p. 139); “Me senti estagnada, a vida completamente estagnada. Nunca ia mudar. [...] Tomei dois valiums e caí no sono no sofazão marrom de veludo que parecia um caixão. [...] Achei que a minha morte ia ser assim. E adorei" (MYLES, 2019, p. 124); "Eu estava em Falmouth ficando bêbada e curtindo a noite, pegando mais e mais caras em seus carros esportivos. Minha tristeza só me deixou mais intrigante" (MYLES, 2019, p. 106); “Ficar bêbada na beira do mar fazia com que eu me sentisse parte da natureza" (MYLES, 2019, p. 99). O que todos esses trechos (e outros) têm em comum é a consciência de que Eileen quer se desfazer da obrigação de ser uma mulher considerada "boa". Viver entorpecida é uma prática de desobrigar-se de um sistema que a deseja normalizada como uma mulher que pretende se casar, ter filhos e manter uma família feliz. Credo.

Se o álcool e as drogas são elementos que a desfazem socialmente, é necessário também pensar como essa escolha está profundamente associada a um processo de desidentificação. Eileen se reconhece como mulher em uma sociedade na qual seu corpo é tratado ora como receptáculo moral, ora como objeto de desejo descartável. Como forma de recusar o seu corpo no jogo binário do essencialismo sobre as mulheres, Eileen escolhe o abuso das substâncias para confrontar qualquer outra decisão considerada sensata. Eileen escolhe fracassar:

Fracassar é algo que pessoas queer fazem e sempre fizeram excepcionalmente bem; para pessoas queer, o fracasso pode ser estilo, citando Quentin Crisp, ou um modo de vida, citando Foucault, e pode contrastar com os cenários sombrios de sucesso que dependem de "tentar e tentar novamente". (HALBERSTAM, 2020, p. 21)

Como sublinha Halberstam, narrativas de/sobre fracasso podem nos ensinar muito sobre o que significar inadequar-se em uma sociedade que busca 
assimilação e homogeneização como processo de progresso. Recusar essa visão de progresso é uma tarefa que Myles descreve em Chelsea Girls. Não quero dizer que o fracasso deva ser lido como uma forma utópica de política, afinal, há toda sorte de sofrimentos; mesmo assim, penso que o fracasso como modo de se posicionar no mundo permite, como demonstra Eileen em suas relações com drogas, sexo e submundos, desfazer a narrativa de sucesso que muitos desejam. Interromper essa narrativa de progresso com cenas sobre estar bêbada, suja e incapaz de agir no mundo significa indicar que as próprias narrativas da felicidade são elementos complexos que ignoram ou escolhem ignorar as nuances de vidas que atravessam os sujeitos envolvidos. Mesmo quando buscava estar "limpa", Eileen descreve sua sensação de infelicidade em relação ao sistema. Ao ler jornais com o intuito de se descobrir no mundo a partir do mundo das letras, Eileen percebe que algo está fora do lugar:

Eu não poderia estar pior. Estava descendo para tomar um café e ler o Boston Globe para me sentir um pouco melhor. Eu fazia de tudo para me sentir melhor. De todo coração, só queria estar morta. [...] Eu estava tentando achar o meu lugar no mundo com tanto empenho que ainda tinha expectativas sobre o que encontraria no Boston Globe. (MYLES, 2019, p. 97, grifos no original)

Ler o jornal era uma forma de buscar relatos possíveis de pessoas como ela, tentar estabelecer uma relação entre a sensação de inadequação e as páginas que narram a sociedade. Entretanto, Eileen ressalta que se sente mal e que folheava o jornal com empenho, parecendo buscar uma página na qual encontraria rostos de pessoas tão sujas, pobres e desprezíveis como ela. Resta, então, escolher não participar desse projeto de progresso ao se aproximar de outros signos considerados imorais - as bebidas, as festas intermináveis, as drogas etc.

É importante sinalizar que não trato o torpor como um estado de elogio ou uma saída utópica. Pelo contrário, quando Eileen recusa os valores 
heteronormativos, ela compreende que para evitar outros sentimentos, o torpor é uma opção viável. Pelo torpor ela reconhece que é possível recusar o sofrimento destinado aos que não concordam com os valores heteronormativos, afinal, o sofrimento é uma forma de punir sujeitos que pisam fora da linha estabelecida. Fazer esses sujeitos dissidentes sofrer é uma produtiva retórica que até hoje possui seus efeitos nas instituições.

Dizer que o torpor é uma alternativa escolhida por Eileen é sublinhar que ela também sofre pelo seu constante estado de desconexão com a realidade. Encontrar-se em um estado no qual qualquer sentimento parece ser uma profunda alegria porque não há reconhecimento crítico é perigoso e Eileen sabe disso:

Fumei muitos Marlboros por ela. Você é uma alcoólatra, Eileen. Não, não sou. Você ficou bêbada na noite passada. Sim. Você fica bêbada toda noite. Não. Grande coisa! ela ria. Eu achava que por ser uma alcoólatra eu não estava à altura dela. Eu gostava dela porque ela tinha sido estuprada e porque ela era difícil e porque ela tinha uma filha pequena e porque ela me olhava nos olhos e ria de mim, e me provocava como se eu fosse um homem. Era assim que eu sentia. Nunca me senti tão constrangida na vida. (MYLES, 2019, p. 128)

Ao descrever sua relação conflituosa com Jane, Eileen traz a voz de sua amante que a questiona ("Você fica bêbada toda noite."), a envergonha e a faz sentir constrangida. Embora reconheça que estar bêbada toda noite a torna mal vista até mesmo pelas suas relações afetivas, Eileen continua bebendo. Há ainda uma controversa identificação com Jane e o estupro. Mais tarde em Chelsea Girls, Eileen relata que fora estuprada pelo irmão de uma amiga com seus amigos e percebe que há um traço entre suas experiências e as de Jane, elementos que o jornal que ela folheava jamais poderia trazer:

Eu estava dolorosamente entorpecida. Fui estuprada, certo? Mesmo que eu não saiba direito o que aconteceu. É assim que me sinto. Um grupo de garotos suburbanos bonitos, dezoito ou dezenove, assim como que, que já 
tinham o próprio carro me destruíram [sic] por dois motivos: eu estava bêbada, eles não me conheciam. Escrevi meu nome na areia com o dedo do pé. EILEEN MYLES. É, eu sou essa. E em seguida apaguei com o pé. (MYLES, 2019, p. 174)

Nesse momento com Jane, Eileen se identifica com sua amante não só pelo estupro que são experiências nas quais ambas estavam vulneráveis, mas também pelo que ela sente - como um homem. Identificar-se com dois elementos complexos e problemáticos - a violência sexual e a presença do masculino em relacionamento lésbico - é justamente uma forma de negociar sentidos que permitem que Eileen possa viver naquele sistema que a enxerga como descartável.

Em algum nível, para Eileen, estar suja, bêbada e drogada é uma forma de buscar a completude de si. Ao deslocar a imagem da violência sexual, questionase a leitura de que estar suja, bêbada e drogada seria um mecanismo de defesa de Eileen para não lidar com o trauma sexual, uma fuga da responsabilidade de lidar com o trauma. Leio de maneira distinta esse deslocamento da narrativa: estar entorpecida é um laço com uma completude de si que já estava bêbada antes da violência sexual. Eileen sinaliza sua rejeição ao estupro como uma narrativa central porque parece reconhecer que a violência sexual é apenas mais um dos sofrimentos impostos aos corpos dissidentes: mulheres que não estão bêbadas também são estupradas, logo estar bêbada não é o motivo. O poder da estrutura heteropatriarcal, em seu diálogo com as ferramentas heteronormativas, é desestabilizado pela narrativa de Eileen que repele a associação entre entorpecimento e estupro. Assim, novamente, é necessário pensar o entorpecimento para além de um mero estar no mundo sem sentimentos porque há algo a ser sentido e esse desejo pelo algo a ser sentido é complexo demais para ser reduzido a um fator único e isolado. Não por acaso, após o estupro, Eileen escreve seu nome na areia como se dissesse a si mesma que estava ali ainda e que aquela narrativa de trauma não poderia definir sua existência. Assumir o torpor 
é, então, assumir controle de sua própria narrativa contra uma sociedade que a pune tanto por ser o que deseja quanto por burlar as fronteiras estabelecidas.

O estado de entorpecimento é uma trajetória de desconfiança. O senso de realidade fica borrado e qualquer movimento se torna um passo suspeito. Tornase facilmente o objeto a ser evitado em muitos círculos, revelando os limites de diversos espaços. Entretanto, esse mesmo torpor que imobiliza em algum nível permite outras reflexões:

Eu desconfio dos sonhos. É só seu cérebro revivendo informações sem utilidade, defendendo-se em outra dimensão, fazendo filmes de seus próprios medos e você acorda aterrorizado ou confortado por alguma coisa que nunca aconteceu ou até mesmo insatisfeito e você quer mais porque é tudo o que você tem. Sonhar é como beber sozinho, quanto menos você vive mais você sonha, e os sonhos ficam mais fantásticos e absurdos. (MYLES, 2019, p. 199-200)

Eileen descreve que é mais fácil desistir e "viver seus próprios sonhos em vez de viver coisas com um amigo" (MYLES, 2019, p. 199), afinal, sonhar é como beber sozinho: pensar nos próprios prazeres pequenos e ignorar o mundo lá fora. Mesmo com todas as desconfianças depositadas nela, Eileen desenvolve sua própria forma de existir e foge das narrativas de progresso que a tornariam uma mulher menos "suja". Dessa forma, pensar o mundo a partir de locais problemáticos revela como a estrutura social está organizada para produzir determinadas formas de existir.

\section{PENSAMENTOS FINAIS}

Ao me aproximar de Chelsea Girls, meu objetivo era tentar compreender como a protagonista Eileen não só recusa a estrutura heteronormativa, que a queria uma mulher heterossexual, casada e com filhos, mas também uma perspectiva de ser uma mulher lésbica politicamente ativa. Essa curiosa escolha 
pela recusa de sistemas, balizada em constante uso de álcool, cigarro e sexo, se tornou objeto de interesse e crítica. Propus indagar aqui como essa recusa do sistema ressignificava o entorpecimento como forma afetiva de existência, sublinhando que o que parece ser imobilizante ou despotencializador pode, também, ser um movimento de questionamento possível.

Chelsea Girls é uma obra literária que, como sublinha Heather Love (2009), desafia a própria ideia de um cânone literário LGBTQ+. Ao recusar uma ação política nos caminhos mais tradicionais, Chelsea Girls não oferece uma protagonista feliz que se encaixa em padrões políticos de engajamento na luta contra a discriminação. Pelo contrário, Eileen escolhe o entorpecimento como forma de engajar-se com o mundo, gerando percepções de que seria uma mulher drogada e suja que não consegue fazer o que deveria ser feito. Enxergo, todavia, nessa proposta de existir uma potência afetiva, mesmo que retrógrada ou feia para alguns. Eileen negocia sua existência a partir de ações desidentificatórias e consegue sinalizar que os sentimentos negativos não a tornam um ser único e exclusivamente abjeto: destoando dos vínculos tradicionais, suas relações com o mundo ilustram que, entre álcool e drogas, sexo e sujeira, existe uma pessoa.

Parece-me importante pensar que romances como Chelsea Girls não só nos aproximam de determinadas realidades abjetas que estão em constante negociação com o sistema, mas principalmente nos confrontam com elementos que nos afastam da aparente cômoda estabilidade de modos de vida contemporâneos. Assim, acredito que qualquer negociação dos afetos negativos produzidos na/pela obra deva indagar quais os resultados políticos possíveis, mesmo quando determinadas temáticas nos desconcertam. Questões como "Será que Eileen deveria parar de beber?" ou "Por que ela não decide viver uma vida limpa?" não me interessam porque elas exalam um teor de moralidade que o romance se recusa a discutir. Dessa forma, as questões que me incomodam são muito mais aquelas que me forçam a pensar o que pode ser apreendido sobre a 
vida a partir de Eileen - "O que as recusas de Eileen podem me dizer sobre a nossa sociedade?" Essa, sim, é uma pergunta que me interessa. Essa, sim, é uma pergunta sobre os cantos sujos que não querem ser varridos para baixo do tapete.

\section{REFERÊNCIAS}

AHMED, Sara. The Promise of Happiness. Durham: Duke University Press, 2010.

BERLANT, Lauren. Cruel Optimism. Durham: Duke University Press, 2011.

BOURCIER, Sam. Homo Inc.Orporated: O triângulo e o unicórnio que peida. Tradução de Marcia Bechara. São Paulo: n-1 edições, 2020.

BUTLER, Judith Butler. Problemas de Gênero: Feminismo e subversão da identidade. Tradução de Renato Aguiar. Rio de Janeiro: Civilização Brasileira, 2015.

DESPENTES, Virginie. Teoria King Kong. Tradução de Márcia Bechara. São Paulo: n-1 edições, 2016.

HALBERSTAM, Jack. A Arte Queer do Fracasso. Tradução de Bhuvi Libanio. Recife: CEPE, 2020.

HALBERSTAM, Jack. Gaga Feminism: Sex, gender, and the end of normal. Boston: Beacon Press, 2012.

HALBERSTAM, Judith (Jack). In a Queer Time E Place: Transgender bodies, subcultural lives. New York: New York University Press, 2005.

HURN, Rachel. Marks on Paper: Eileen Myles's Chelsea Girls. The Paris Review, New York, 2013. Disponível em https://www.theparisreview.org/blog/2013/03/14/marks-onpaper-eileen-myles-chelsea-girls/. Acesso em 02 Jul. 21.

KIPNIS, Laura. Against Love: A polemic. New York: Vintage Books, 2004.

KLINGER, Diana. Literatura e Ética: Da forma para a força. Rio de Janeiro: Rocco, 2014.

LOVE, Heather. Feeling Backward: Loss and the politics of queer history. Cambridge \& London: Harvard University Press, 2009.

MENEZES, Léa Santana de. Quando o obsceno compõe a cena: outras feminidades para compor novos feminismos. In: SOARES, Mayana Rocha; BRANDÃO, Simone; FARIA, Thais (Orgs.). Lesbianidades Plurais: Outras produções de saberes e afetos. Salvador: Editora Devires, p. 119-128, 2019.

MUÑOZ, José Esteban. Disidentifications: Queers of color and the performance of politics. Minneapolis e Londres: University of Minnesota Press, 1999.

MYLES, Eileen. Chelsea Girls. Tradução de Bruna Beber. São Paulo: Todavia, 2019.

NGAI, Sianne. Ugly Feelings. Boston: Harvard University Press, 2005. 
TACKETT, Justin. Stanford scholars debate the moral merits of reading fiction. Stanford Report, $\quad$ Stanford. 2014. Disponível em https://news.stanford.edu/news/2014/february/morals-ethics-literature-022114.html. Acesso em 02 Jul. 21.

Nota do editor:

Artigo submetido para avaliação em: 29 de março de 2021.

Aprovado em sistema duplo cego em: 14 de julho de 2021. 